\section{Kidney \\ Bloód Pressure Research}

Kidney Blood Press Res 2016;41:593-603

\title{
Renalase Secreted by Human Kidney HEK293T Cells Lacks its N-Terminal Peptide: Implications for Putative Mechanisms of Renalase Action
}

\author{
Valerii Fedchenko Arthur Kopylov Nadezhda Kozlova Olga Buneeva \\ Alexei Kaloshin Victor Zgoda Alexei Medvedev \\ Institute of Biomedical Chemistry, Moscow, Russia
}

Key Words

Renalase $\cdot$ HEK293T cells $•$ Secretion $・ N$-terminal peptide

\begin{abstract}
Background/Aims: Renalase is a recently discovered flavoprotein involved in regulation of blood pressure. Altered renalase levels have been found in blood of patients with end stage renal disease. The antihypertensive effect of circulating renalase is attributed to putative FADdependent monoamine oxidase activity demonstrated by some authors. Being synthesized as an intracellular flavoprotein renalase requires the presence of its $\mathrm{N}$-terminal peptide for FAD accommodation. However, conventional routes of export of secretory proteins outside the cell usually include cleavage of their $\mathrm{N}$-terminal peptide. The aim of this study was to investigate whether renalase is secreted by HEK293T cells as a full length protein (via proposed nonconventional pathway) or its export is accompanied by the loss of its $\mathrm{N}$-terminal peptide. Methods: We have expressed human recombinant renalase-1 in human kidney HEK293T cells and analyzed this protein inside the cells and in the extracellular medium for the presence of the N-terminal peptide by using high resolution targeted MS/MS. Results: Intracellular renalase contained clearly detectable $\mathrm{N}$-terminal peptide, which was absent in extracellular renalase. Conclusions: Lack of the N-terminal peptide, the structural precondition for FAD binding, suggests that extracellular (circulating) renalase acts in a FAD-independent manner and mechanisms of its action are not associated with FAD.
\end{abstract}




\section{Kidney Blood Pressure Research}

\section{Introduction}

Renalase is a recently discovered secretory protein involved in regulation of blood pressure [1-6]. Possible mechanisms of renalase action that would account for the decrease of blood pressure remain elusive [4-6]. Nevertheless, administration of recombinant human renalase lowered arterial pressure in Sprague-Dawley rats [1,7]. Recently it has been also demonstrated that in Sprague-Dawley rats with chronic kidney disease (CKD), modeled by subtotal nephrectomy (5/6), renalase gene delivery attenuated hypertension [8]. Clinical studies on representative groups of patients revealed altered levels of blood renalase in patients with hypertension. For example, Maciorkowska et al. reported that blood renalase levels were higher in hypertensive patients $(n=121)$ than in normotensive volunteers $(n=27)$ [9]. Another study demonstrated that plasma renalase levels were lower in hypertensive patients after surgical repair of coarctation of aorta $(n=50)$ than in controls $(n=50)$ [10]. Monitoring of plasma and urine renalase levels in 26 patients with end stage renal disease (ESRD) before and after transplantation of cadaver kidneys revealed gradual normalization of increased renalase levels both in blood and urine [11]. All these data point to a clear need for better understanding of structural and functional characteristics of this protein.

All known renalases synthesized in eukaryotic and prokaryotic cells contain cleavable N-terminal signal peptide (residues 1-17) [3-7, 12-14] required for extracellular secretion of renalase (Fig. 1). It overlaps with the minimal Rossman fold (residues 2-32) responsible for accommodation of the adenine nucleotide moiety of $\operatorname{FAD}[5,7,12]$. The presence of non-covalently bound FAD was originally demonstrated by the Aliverti's group in purified recombinant renalase [7, 12] and further confirmed by other laboratories $[6,13,15]$.

Based on some renalase sequence homology with amino acid sequences of monoamine oxidases, it was originally proposed that the hypotensive effect of renalase may be attributed to FAD-dependent degradation of circulating catecholamines [1, 16, 17]. In this context, some authors reported that serum and especially urinary samples (containing renalase protein) generated hydrogen peroxide in the presence of amine substrates $[11,17]$. However, others $[5-7,12,18]$ failed to detect any amine oxidase activity measured by independent methods. Subsequent studies have demonstrated that renalase acts as FAD-dependent $\alpha$-NAD(P)H oxidase/anomerase converting isomeric forms of $\beta$-NAD(P)H, which could be inhibitory to intracellular metabolic processes $[6,13,19]$. It was also shown that human recombinant renalase- 1 contained FAD and catalyzed adrenaline oxidation in a NAD(P)H dependent manner; its administration to animals lowered not only arterial pressure but also plasma adrenaline concentration [17]. However, this observation was not confirmed in another laboratory $[6,18]$.

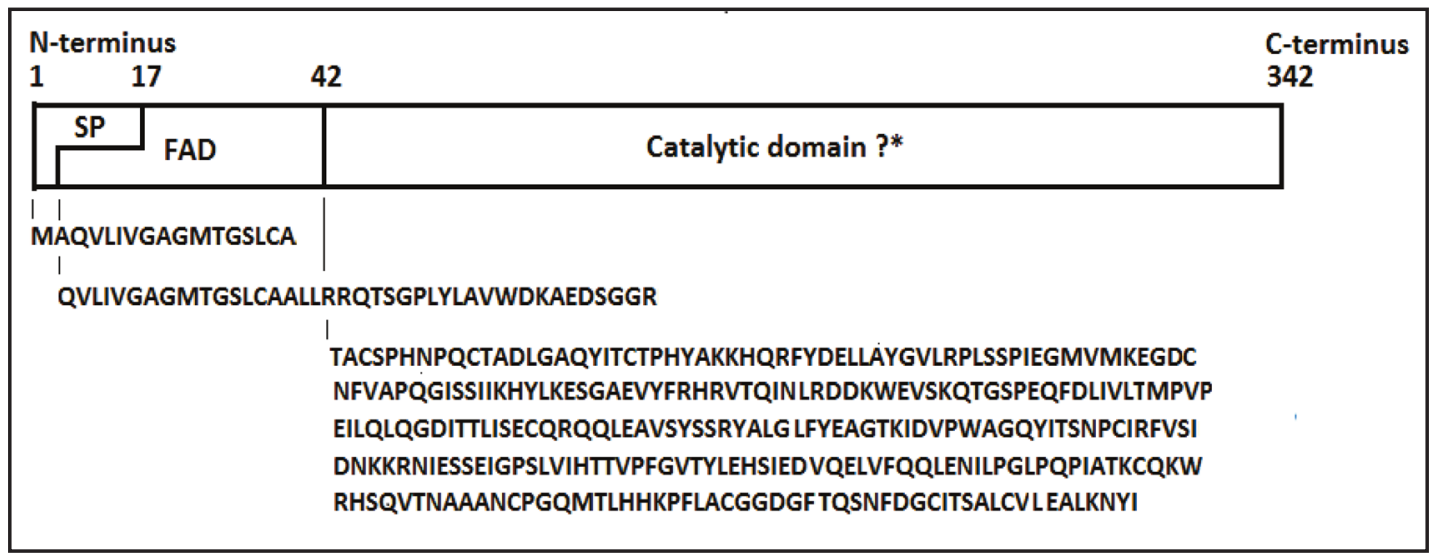

Fig. 1. The scheme of human renalase with its $\mathrm{N}$-terminal peptide. The question mark indicates lack of precise information on the amino acid residues involved in the catalytic domain. 


\section{Kidney \\ Blood Pressure Research}

Recently, endogenous NADH dependent renalase activity was detected both in plasma and urinary samples of kidney transplant recipients [11]. All these reactions catalyzed by or attributed to renalase require the presence of the FAD cofactor, which can be accommodated by full-length renalase (including the N-terminal peptide). Whether this FAD molecule is preserved in extracellular renalase(s) remains unknown.

It should be noted that extracellular renalases have been detected in blood, urine and also in supernatants of cell cultures by means of Westen blot [1, 20-22] or ELISA tests [11, 20, 23-26].

Evaluation of the intracellular renalase protein is also based on the use of antibodies [27-29]. All these approaches do not detect either the $\mathrm{N}$-terminal sequence (involved in cofactor accommodation) or the cofactor itself. Although Desir et al. [3] mentioned in their review that human renalase purified from blood contains the $\mathrm{N}$-terminal signal peptide, no experimental evidence supporting this statement was presented to validate this statement. Thus, identification of the $\mathrm{N}$-terminal signal peptide in extracellular renalases is very important due to proposed speculations on FAD-dependent mechanisms of renalase activity both in serum and urine $[1,3,11,17]$ and contradictory reports on catecholaminemetabolizing activity in this protein $[1,4-6,18,20]$.

Recently, using the full-length recombinant renalase as control of tryptic patterns, we found that human urinary renalase isolated by means of immunoaffinity chromatography lacked the N-terminal peptide, while in the recombinant protein this peptide was clearly detected [15]. As shown by molecular simulations performed using the renalase crystal structure obtained by the Aliverti's group [12], the absence of the N-terminal signal peptide excludes the possibility of FAD binding by the truncated protein [15].

Where cleavage of the N-terminal peptide occurs still remains to be elucidated. Although possible formation of the truncated renalase during urine storage may be ruled out [15], cleavage of the $\mathrm{N}$-terminal peptide may occur: (a) during secretion of intracellular renalase from the cell; (b) in blood circulation; (c) during urinary excretion of proteins. Studying adrenaline induced renalase secretion by human renal proximal tubular epithelial cells (HK2) Wang et al. [22] detected this protein in the extracellular medium. However, Western blot analysis used for its detection was not aimed at investigation of the presence or absence of its N-terminal peptide.

In order to evaluate the first and most likely possibility (of N-terminal peptide cleavage of renalase) we have investigated human recombinant renalase in lysates of НЕК293T cells and in the extracellular cultivation medium for the presence of its $\mathrm{N}$-terminal peptide. Earlier these cells were already used for transfection with renalase gene and elaboration of the protein product [29].

\section{Materials and Methods}

\section{Reagents}

Trifluoracetic acid (TFA) was purchased from Fluka, Germany; triethylammonium bicarbonate (TEAB) was purchased from Sigma, St. Louis, MO, USA; heptafluorobutyric acid (HFBA) was purchased from Acros, Geel, Belgium; formic acid from Merck, Germany; acetonitrile from Fisher Chemical, Leicestershire, UK. Trypsin modified sequencing grade was obtained from Promega, Madison, WI, USA; flavin adenine dinucleotide disodium salt hydrate (FAD) was purchased from Sigma, St. Louis, MO, USA. A custom polyclonal sheep antibody was raised against human recombinant renalase1 and purified by Pocard Ltd. (Moscow, Russia). A monoclonal anti-rabbit/sheep IgG antibody conjugated with horseradish peroxidase was from IMTEK (Moscow, Russia) (see also [14]).

Cell cultures, plasmids and preparation of the eukaryotic vector pcDNA-hRenI

Human embryonic kidney 293 transformed cells (HEK 293T cells) were purchased from the American Type Culture Collection. 


\section{Kidney Blood Pressure Research}

Fig. 2. The vector containing the fulllength renalase gene nucleotide sequence encoding native renalase.

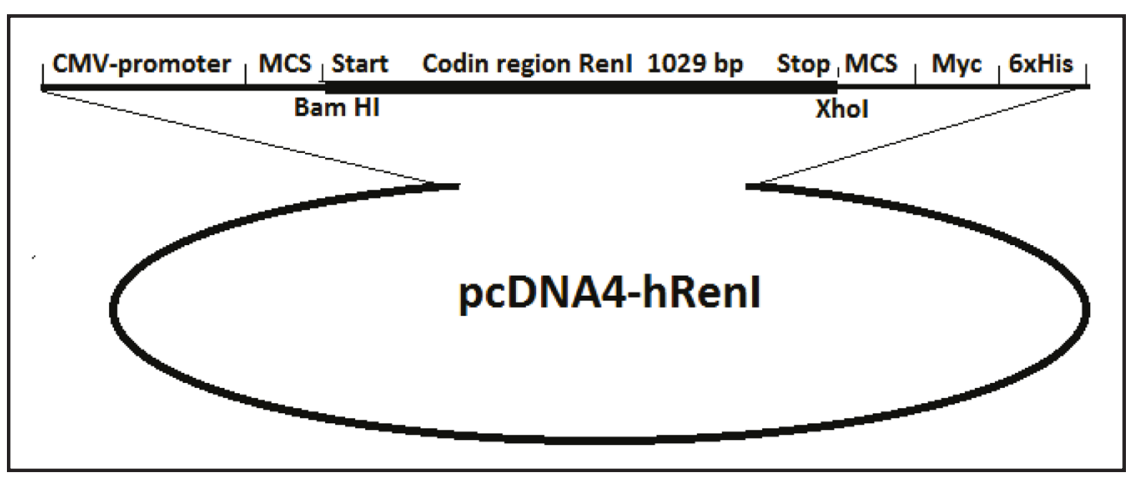

The pcDNA-hRenI vector was prepared using a commercially available vector pcDNA4 myc-His B (Invitrogene) and a DNA fragment containing the full-length coding region of the renalase-1 gene. The latter was obtained by amplification of the corresponding nucleotide sequence of the plasmid pET-hRenI, in which the renalase-1 gene contained an additional sequence coding a hexahistidine tag [14]. The renalase gene coding sequence was inserted by BamHI/XhoI restriction sites. Amplification of the DNA fragment was performed using the forward primer 5'-gagctcggatccgaaatggaagcgcaggtgctgatcgtgggc, including a BamHI restriction site and a Kozak sequence and the reverse primer 5 '-tctagaccgagcgcagatgggaaatccaatcgcc, including the renalase stop codon and a XhoI restriction site (Fig. 2). Subsequent cloning in E. coli cells resulted in selection of a cell clone carrying the pcDNA-hRenI vector. Its sequencing has shown that the coding region of the renalase-1 gene did not contain any additional nucleotides (that would code additional amino acid residues).

\section{Expression and isolation of renalase}

The constructed plasmid vector pcDNA4 hRen1 was transfected into eukaryotic HEK293T cells, which were plated into $10 \mathrm{~cm}$-Petri dishes ( 7 million cells per dish) $5 \mathrm{~h}$ before transfection and cultivated in DMEM medium (PanEco, Russia) containing 10\% FCS (PAA Laboratories), $4 \mathrm{mM}$ glutamine (PanEco,) and antibiotics penicillin and streptomycin ( 50 units $/ \mathrm{mL}$ and $50 \mu \mathrm{g} / \mathrm{mL}$, respectively; PanEco). After the incubation cells were transfected by means of a mixture containing the transfected reagent FuGene 6 (Promega, USA) and the plasmid vector pcDNA4 hRen1 in DMEM medium (5 $\mu$ g plasmid DNA and $15 \mu \mathrm{L}$ of FuGene 6 per each plate).

The mixture preincubated at room temperature for 30 min was then added to the cell culture, which was cultivated at $37^{\circ} \mathrm{C}$ for $16 \mathrm{~h}$. After this incubation the transfection medium was removed and replaced with fresh DMEM medium containing $4 \mathrm{mM}$ glutamine, and antibiotics penicillin and streptomycin (50 units $/ \mathrm{mL}$ and $50 \mu \mathrm{g} / \mathrm{mL}$ respectively). Under these conditions transfected HEK293T cells were incubated for $30 \mathrm{~h}$. After incubation, the cultivation medium was harvested, cleared by low speed centrifugation (1000 rpm for 5 min; Heraeus Megafuge 40 centrifuge; Thermo Scientific USA) and filtered through a sterile PVDFFilter with a pore diameter of $0.45 \mathrm{~m}$ (Millipore). Based on renalase isolation from human urine samples [14] the protein concentrated by $75 \%$ ammonium sulfate precipitation was then dissolved in $50 \mathrm{mM}$ Tris$\mathrm{HCl}$ buffer, containing $5 \mathrm{mM} \mathrm{EDTA}, \mathrm{pH} 8.0$, and stored at $-20^{\circ} \mathrm{C}$. The cell monolayer was mechanically scraped off from the substrate, washed with saline, and sedimented at $5000 \mathrm{rpm}$ for $10 \mathrm{~min}$ using the Eppendorf centrifuge 5415R. The resultant cell pellet was suspended in $50 \mathrm{mM}$ Tris- $\mathrm{HCl}$ buffer, containing $5 \mathrm{mM} \mathrm{EDTA}$, $\mathrm{pH}$ 8.0, sonicated in an ice bath and after removal of cell debris by centrifugation $(15000 \mathrm{rpm}$ for $20 \mathrm{~min}$, Eppendorf centrifuge $5415 \mathrm{R}$ ) stored at $-20^{\circ} \mathrm{C}$.

Transfection efficiency was controlled using the plasmid vector pTagGFP2-N (Evrogen). According to TagGFP2 fluorescence the transfection efficiency was about $65 \%$.

SDS-electrophoresis of proteins isolated from in the conditioned medium and cell lysates was performed in 15\% polyacrylamide gel [30]. Immunoblotting was performed by the method of Gallagner et al. [31] as described in Fedchenko et al. [14] using sheep antibody to renalase 1 and horseradish peroxidase conjugate with rabbit anti-sheep immunoglobulin.

Gel slices corresponding to the range of molecular masses from $45 \mathrm{kDa}$ to $\sim 25 \mathrm{kDa}$ evaluated by both protein molecular mass markers and purified recombinant renalase 1 as a reference were used for 


\section{Kidney Blood Pressure Research}

Fedchenko et al.: Renalase Release From HEK293T Cells Without N-Terminal Peptide

subsequent in-gel digestion with trypsin (see below). The range of molecular masses covered by gel slices roughly corresponded to full-length renalase and processed renalase (lacking its N-terminal peptide).

\section{In-gel digestion with trypsin}

Gel slices with putative renalase protein were cut into small pieces. After washing and destaining gel was dried under vacuum and rehydrated in $10 \mu \mathrm{L}$ of trypsin $100 \mathrm{ng} / \mu \mathrm{L}$ in the supplied $1 \mathrm{mM}$ hydrochloric acid for $5 \mathrm{~min}$ at $4^{\circ} \mathrm{C}$ following addition of $20 \mu \mathrm{L}$ of $75 \mathrm{mM}$ TEAB. The reaction of tryptic digestion was performed overnight at $37^{\circ} \mathrm{C}$ under stirring at $1200 \mathrm{rpm}$ for $5 \mathrm{~min}$ every $45 \mathrm{~min}$ [15]. Peptides were extracted from gel pieces via three changes by $0.5 \%$ TFA. For each change $100 \mu \mathrm{L}$ of $0.5 \%$ TFA was added to the gel pieces, which were subsequently incubated for $20 \mathrm{~min}$ at gradient temperature from $40^{\circ} \mathrm{C}$ to $65^{\circ} \mathrm{C}$. The collected fractions were dried under vacuum at $30^{\circ} \mathrm{C}$ for $60 \mathrm{~min}$ and reconstituted in $10 \mu \mathrm{L}$ of $0.1 \%$ formic acid for LC-MS analysis.

\section{Liquid chromatography-Mass spectrometry analysis}

Proteomic profiling of samples exposed to tryptic digestion was performed using a high resolution Q-Exactive mass spectrometer (Thermo Scientific, Waltham, MA USA). The full proteome experiment datadependent MS/MS method was used for proteomic profiling and a targeted-MS/MS method (t-MS2) was designed to detect the N-terminal peptide of renalase. In both cases the instrument was operated in positive ionization mode and equipped with an Easy-Spray® ion source. The capillary voltage was set at $1.9 \mathrm{kV}$ and transfer capillary temperature was $280^{\circ} \mathrm{C}$, the S-lens RF level was $60 \%$. Internal calibration was enabled during the whole analysis using user-defined lock masses $(\mathrm{m} / \mathrm{z}=371.10124,445.12002$ and 741.1952). In the data-dependent MS/MS analysis the MS scan was performed at 70K resolution with an AGC target value of $1 \mathrm{e} 6$ ions for $128 \mathrm{~ms}$ in range of $400-1500 \mathrm{~m} / \mathrm{z}$ following top N10 MS/MS scans at 35K resolution with automatic gain control (AGC) target of $1 \mathrm{e} 5$ for $48 \mathrm{~ms}$, mass isolation window of $2 \mathrm{Th}$ ( $\pm 1 \mathrm{amu}$ ) and first fixed mass of $150 \mathrm{~m} / \mathrm{z}$. The normalized collision energy was $35 \mathrm{eV}$ and applied in the stepwise manner with $\pm 25 \%$ shift. Apex trigger mode and dynamic exclusion were used. Ions with charge states $z=1+, \mathrm{z}>4+$ and with unassigned charge were excluded from analysis.

The N-terminal peptide of renalase was detected by a targeted MS/MS method as described by Fedchenko et al. [32]. Taking into consideration that newly synthesized proteins often undergo N-terminal methionine excision (see for example, [33]) we were looking for two the following sequences with and without the first methionine residue: MAQVLIVGAGMTGSLCAALLR (residues 1-21) and AQVLIVGAGMTGSLCAALLR (residues 2-21), respectively.

Due to uncertainty of charge states and the possible dehydration of the precursor ion we created a preliminary inclusion list comprised of 6 available precursor ions: $[\mathrm{M}+2 \mathrm{H}]^{2+},[\mathrm{M}+3 \mathrm{H}]^{3+}$ and $[\mathrm{M}+2 \mathrm{H}-\mathrm{H} 2 \mathrm{O}]^{2+}$ for peptide MAQVLIVGAGMTGSLCAALLR (m/z = 1038.0623, $\mathrm{m} / \mathrm{z}=692.3773$ and $\mathrm{m} / \mathrm{z}=1029.0570$ ) and for peptide AQVLIVGAGMTGSLCAALLR ( $\mathrm{m} / \mathrm{z}=972.5421, \mathrm{~m} / \mathrm{z}=648.6972$ and $\mathrm{m} / \mathrm{z}=963.5368$ ). The MS2 scan was performed with 2 microscans at $140 \mathrm{~K}$ resolution with AGC target of 2e 5 ions for 300 ms and mass isolation window of $1 \mathrm{Th}( \pm 0.5 \mathrm{amu})$. The collision energy was optimized for each precursor ion and defined in the inclusion list at $27 \mathrm{eV}$ for $\mathrm{m} / \mathrm{z}=648.6972\left([\mathrm{M}+3 \mathrm{H}]^{3+}\right), 31 \mathrm{eV}$ for $\mathrm{m} / \mathrm{z}=972.5421\left([\mathrm{M}+2 \mathrm{H}]^{2+}\right)$ and $29 \mathrm{eV}$ for $\mathrm{m} / \mathrm{z}=963.5368\left([\mathrm{M}+2 \mathrm{H}-\mathrm{H} 2 \mathrm{O}]^{2+}\right)$. The different charge state of the defined precursor had to be detected at the same retention time to confirm identification.

\section{Results}

Renalase expression in HEK-293T cells

Transfection of HEK-293T cells with the vector pcDNA4-hRenI carrying renalase gene coding full length renalase (without any additions such as a hexahistidine tag, etc) resulted in appearance of a protein, which was not detected in non-transfected cells (Fig. $3)$. Its molecular mass well corresponded to the calculated molecular mass (37.5 kDa) of human renalase-1. According to the electrophoresis of cell lysates, followed by immunoblot analysis with anti-renalase antibodies, maximal protein expression was observed after cell incubation for two days. Longer incubation of cells (up to four days) was accompanied by 


\section{Kidney Blood Pressure Research}

Fig. 3. Expression of human recombinant renalase-1 in HEK-293T cells. Tracks 1 and 8 - recombinant renalase-1 (containing C-terminal hexahistidine tag) of $39.5 \mathrm{kDa}$, expressed in and isolated from E. coli cells [14]; track C - lysate of intact nontransfected HEK293T cells; tracks 2,3, and 4 - lysate of HEK-293T cells transfected with the renalase gene and cultivated for seven, three, and two days, respectively; tracks 5,6 , and 7 - a fraction of extracellular proteins isolated from the conditioned medium of transfected HEK-293T cells

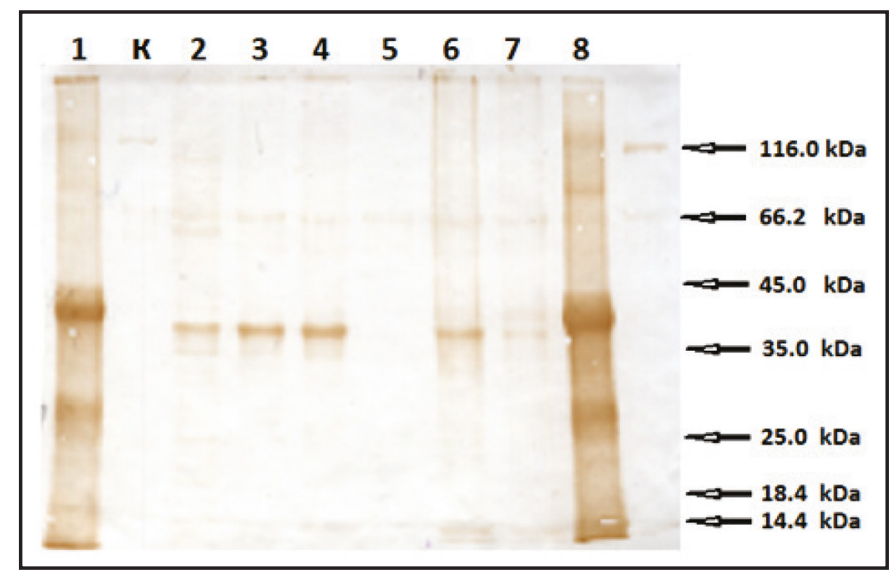
cultivated for seven, three, and two days, respectively. Positions of protein markers are shown on the right.

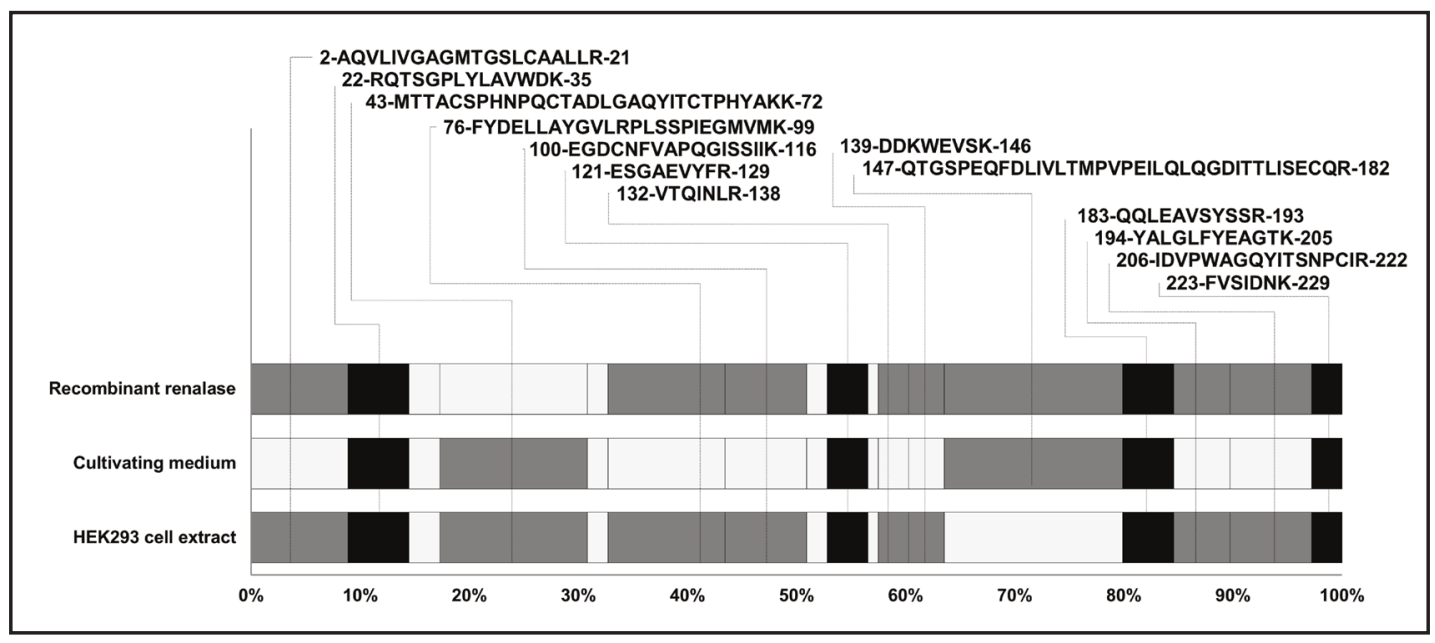

Fig. 4. Comparative distribution of all detected peptides (Table 1) along the amino acid sequences of recombinant, intracellular, and extracellular renalases. Black segments designate peptides detected in all renalases studied; grey segments designate common peptides detected during paired comparison of renalases; missed segments are shown in white.

a decreased content of this protein in cell lysates. In the extracellular medium immunoblot analysis with anti-renalase antibodies revealed appearance of a protein with molecular mass of about $36.0 \mathrm{kDa}$ (Fig. 2). Its highest content in the extracellular (cultivation) medium was observed after four days of cell cultivation.

\section{Detection of renalases in lysates of HEK cells and the cultivation medium}

Renalase was confidently detected in both the lysate of HEK cells and the cultivation medium (Fig. 4). The coverage of amino acid sequence of renalase extracted from HEK cells was basically the same as in the case of purified preparation of human recombinant renalase-1 expressed in Escherichia coli cells and used as a reference standard (Table 1). Although the coverage of amino acid sequence of renalase, detectable in the cultivation medium, was somewhat lower than in the case of the purified recombinant renalase 1 and renalase detected in the cell lysate, such coverage is usually considered as reasonable for reliable identification of a protein of interest. 


\section{Kidney Blood Pressure Research}

Table 1. Renalase peptides detected in lysates of human НЕК293T cells, cultivation medium

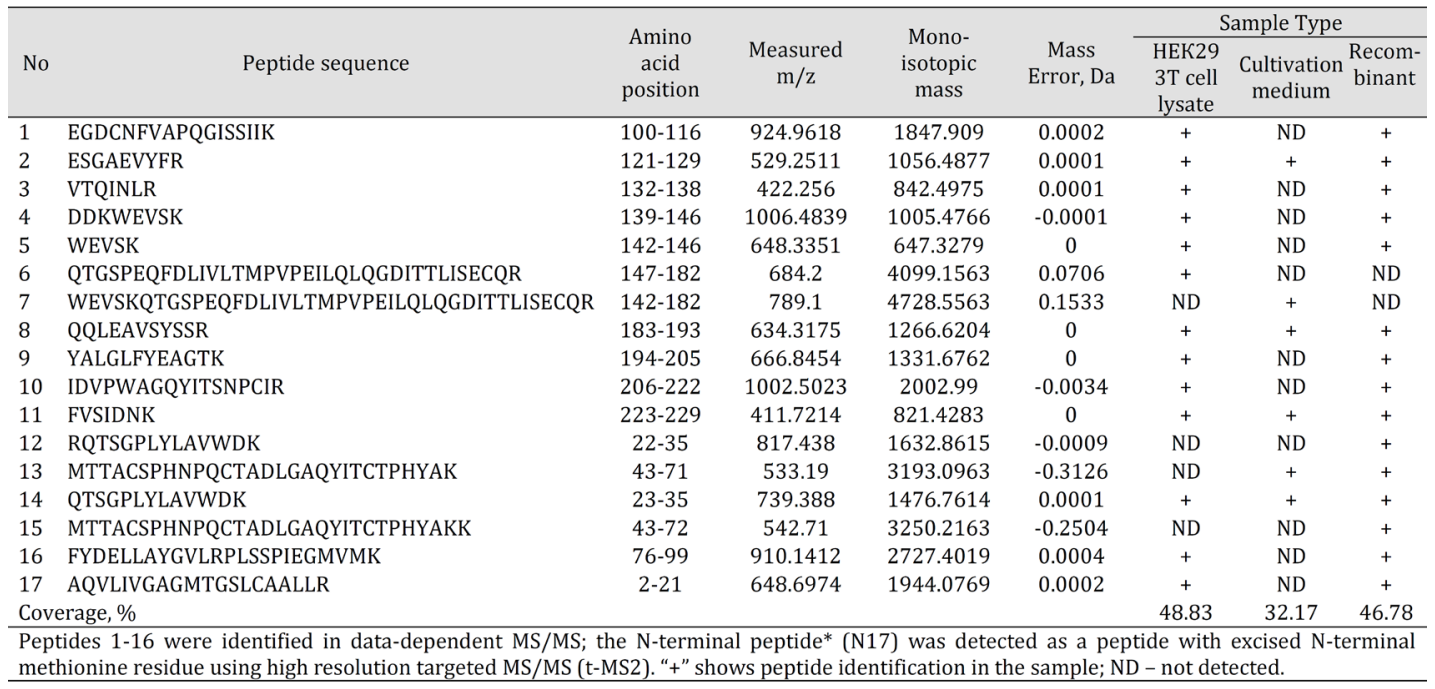

The targeted search for the $N$-terminal peptide in human urinary renalase

In accordance with our previous study, the N-terminal peptide was detected in human recombinant renalase expressed in E. coli cells [15]. Under our experimental conditions, the $\mathrm{N}$-terminal peptide was detected only in human renalase extracted from HEK cells, a polypeptide containing residues 2-21 (Fig. 4, Table 1). Lack of the first methionine residue deduced from corresponding nucleotide gene sequence may be attributed to the well-known process of $\mathrm{N}$-terminal methionine excision observed commonly with newly synthesized proteins [33]. In contrast to intracellular renalases (expressed in E. coli and HEK cells) we did not find any convincing evidence for the presence of the N-terminal peptide in renalase confidently identified in the extracellular medium. The absence of this peptide in renalase isolated from the conditioned medium (as well as the presence of this peptide in other renalase preparations) was confirmed by targeted MS2 (see details in the Materials and Methods Section). In this context it is especially important that in all renalase preparations studied we were able to identify next tryptic peptide (residues 23-35) adjacent to the $\mathrm{N}$-terminal peptide as well as several other peptides of the N-terminal part of renalase (Fig. 4 , Table 1). This suggests that lack of the peptide 2-21 in extracellular renalase is not an experimental artifact and the proteolytic cleavage involves only the $\mathrm{N}$-terminal peptide.

Thus taken together these results obviously mean that extracellular renalase lacks an important region required for accommodation of its FAD cofactor.

\section{Discussion}

HEK293(T) cells are widely used for production of recombinant proteins and their subsequent export into the extracellular space [34]. Taking into consideration that they do not express detectable amounts of own renalase they do represent a very convenient tool for analysis of export of intracellular (recombinant) renalase outside the cell. The latter is especially important as kidneys represent an important source of circulating renalase $[3,21$, 29], which is significantly altered at (end stage) renal disease [21]. It also should be noted that HEK293(T) cells were already used for transfection with the renalase gene (containing one His Tag gene after the coding sequence) [29]. However, the cited study was focused on other problems unrelated to renalase transport outside the cell [29].

In order to rule out any possible effects of additional amino acid stretches (e.g. hexahistidine tags, fused peptides/proteins) we have constructed a vector containing the 


\section{Kidney Blood Pressure Research}

Fig. 5. The scheme accumulating current information about synthesis and excretion of kidney renalase. Renalase is synthesized by kidney cells as a protein containing the $\mathrm{N}$-terminal peptide (shown as a hutched block). Transmembrane translocation of synthesized renalase into the extracellular space (circulation) is accompanied by loss of the $\mathrm{N}$-terminal peptide. Urinary

renalase is excreted as a truncated protein lacking its N-terminal peptide. Asterisks show experimentally confirmed steps in the renalase metabolism (see details in the text).

full-length renalase gene nucleotide sequence encoding native renalase (Fig. 2). The presence of a protein product corresponding to human renalase in HEK293T was demonstrated by Western blot analysis with the anti-renalase antibodies (Fig. 3) successfully used earlier for detection of protein products expressed in a prokaryotic system $[14,15]$. Mass spectrometry analysis of intracellular renalase revealed the presence of an intact $\mathrm{N}$-terminal terminus (see Table 1). Since we analyzed renalase preparations initially subjected to electrophoretic separation, lack of FAD may be well explained by its non-covalent interaction with the renalase protein. Earlier we found [15] that electrophoretic procedure caused a loss of FAD from purified renalases. Mass spectrometry analysis confidently detected recombinant renalase in the cultivation medium of transfected HEK293T cells. However, in contrast to recombinant renalase expressed in the prokaryotic system and in the eukaryotic system (HEK293T cells), renalase presented in the cultivation medium of HEK293T cells did not contain the N-terminal peptide.

Thus, results of the present study provide first convincing evidence that human recombinant renalase expressed in HEK293T cells and secreted into extracellular medium lacks its $\mathrm{N}$-terminal peptide. This argues against possibility of renalase secretion from these cells via a nonconventional pathway as a full-length protein [3]. Since the cells are immediate source of extracellular renalase, the absence of the N-terminal peptide suggests that renalases detected in biological body fluids cannot contain their N-terminal peptide (Fig. 5). This is supported by our recent observation that urinary renalase lacks its $\mathrm{N}$-terminal peptide and formation of this truncated renalase cannot be attributed to urinary/blood proteases [15]. Thus, considering all possible scenarios of cleavage of the renalase $\mathrm{N}$-terminal peptide it appears that the cleavage occurs during secretion of intracellular renalase from the cell, rather than in blood circulation or during urinary excretion of this protein.

Results of our study strengthen the current viewpoint on distinct physiological roles of intracellular and extracellular renalases $[5,15]$. Full length intracellular renalase is a flavoprotein that catalyzes FAD-dependent oxidative conversion of $\alpha-\mathrm{NAD}(\mathrm{P}) \mathrm{H}$ to $\mathrm{NAD}(\mathrm{P})^{+}$ 


\section{Kidney \\ Blood Pressure Research}

and/or oxidative conversion of $\beta$-NADH isomers (inhibiting activity of NAD-dependent dehydrogenases) to $\beta$-NAD $[6,19]$. Extracellular renalase lacks the $\mathrm{N}$-terminal peptide, it cannot accommodate FAD and therefore cannot catalyze FAD-dependent reactions in blood and urine described in the literature $[11,17]$, which are obviously unrelated to the renalase protein. In this context it is especially important that the Desir's group has recently described some effects exhibited by renalase-derived peptide(s) acting in a FAD-independent manner [35] and identified a renalase receptor [36]. Implementation of these "extracellular" effects clearly involves principally different (FAD-independent) mechanisms. These may include (non-enzymatic) regulatory cytokine-like effects [37] of renalase and/or renalase-derived peptides [35]. Such effects could be realized via interaction with the renalase receptor(s) described in the literature [36] and interfered with protein kinase B and the mitogen activated protein kinase (MAPK) signaling [37]. In this context it is interesting that p38 MAPK inhibition ameliorates kidney damage in hypertensive rats [38].

\section{Conclusions}

Secretion of human recombinant renalase by human kidney HEK293T cells is accompanied by cleavage of its $\mathrm{N}$-terminal peptide. Lack of the $\mathrm{N}$-terminal peptide, the structural precondition for FAD binding, suggests that extracellular (circulating) renalase acts in a FAD-independent manner and mechanisms of action of extracellular renalase are not associated with FAD.

\section{Disclosure Statement}

Authors declare that they have no conflict of interest.

\section{Acknowledgments}

Experiments on recombinant renalase expression in HEK293T cells and isolation were supported by the Russian Foundation for Basic research (grant no. 14-04-00624). Mass spectrometry analysis of renalase samples was supported by the Russian Science Foundation (grant no. 14-25-00132).

\section{References}

1 Xu J, Li G, Wang P, Velazquez H, Yao X, Li Y, Wu Y, Peixoto A, Crowley S, Desir GV: Renalase is a novel, soluble monoamine oxidase that regulates cardiac function and blood pressure. J Clin Invest 2005;115:1275-1280.

2 Medvedev AE, Veselovsky AV, Fedchenko VI: Renalase, a new secretory enzyme responsible for selective degradation of catecholamines: achievements and unsolved problems. Biochemistry (Moscow) 2010;75:951-958.

3 Desir GV, Wang L, Peixoto AJ: Human renalase: a review of its biology, function, and implications for hypertension. J Amer Soc Hypertens 2012;6:417-426.

4 Baroni S, Milani M, Pandini V, Pavesi G, Horner D, Aliverti A: Is renalase a novel player in catecholaminergic signaling? The mystery of the catalytic activity of an intriguing new flavoenzyme. Curr Pharm Des 2013;1:2540-2451.

5 Severina IS, Fedchenko VI, Veselovsky AV, Medvedev AE: The history of renalase from amine oxidase to $\alpha$-NAD(P)H oxidase/anomerase. Biomed Khim 2015;61:667-679. 


\section{Kidney \\ Blood Pressure Research}

6 Moran GR: The catalytic function of renalase: A decade of phantoms. Biochim Biophys Acta 2016;1864:177-186.

7 Pandini V, Ciriello F, Tedeschi G, Rossoni G, Zanetti G, Aliverti A: Synthesis of human renalase1 in Escherichia coli and its purification as a FAD-containing holoprotein. Protein Expr Purif 2010;72:244-253.

8 Yin J, Lu Z, Wang F, Jiang Z, Lu L, Miao N, Wang N: Renalase attenuates hypertension, renal injury and cardiac remodelling in rats with subtotal nephrectomy. J Cell Mol Med 2016, doi: 10.1111/jcmm.12813.

9 Maciorkowska D, Zbroch E, Malyszko J: Circulating renalase, catecholamines, and vascular adhesion protein 1 in hypertensive patients. J Am Soc Hypertens 2015;9:855-864.

10 Wybraniec MT, Mizia-Stec K, Trojnarska O, Chudek J, Czerwienska B, Wikarek M, Wiecek M: Low plasma renalase concentration in hypertensive patients after surgical repair of coarctation of aorta. J Am Soc Hypertens 2014;8:464-474.

11 Quelhas-Santos J, Soares-Silva I, Fernandes-Cerqueira C, Simões-Silva L, Ferreira I, Carvalho C, Coentrão L, Vaz R, Sampaio-Maia B, Pestana M: Plasma and urine renalase levels and activity during the recovery of renal function in kidney transplant recipients. Exp Biol Med (Maywood) 2014;239:502-508.

12 Milani M, Ciriello F, Baroni S, Pandini V, Canevari G, Bolognesi M, Aliverti A: FAD-binding site and NADP reactivity in human renalase: A new enzyme involved in blood pressure regulation. J Mol Biol 2011;411:463-473.

13 Beaupre BA, Carmichael BR, Hoag MR, Shah DD, Moran GR: Renalase is an $\alpha$-NAD(P)H oxidase/anomerase. J Am Chem Soc 2013;135:13980-13987.

14 Fedchenko VI, Kaloshin AA, Mezhevikina LM, Buneeva OA, Medvedev AE: Construction of the coding sequence of the transcription variant 2 of the human renalase gene and its expression in the prokaryotic system. Int J Mol Sci 2013;14:12764-7779.

15 Fedchenko VI, Buneeva OA, Kopylov AT, Veselovsky AV, Zgoda VG, Medvedev AE: Human urinary renalase lacks the N-terminal signal peptide crucial for accommodation of its FAD cofactor. Int J Biol Macromol 2015;78:347-353.

16 Li G, Xu J, Wang P, Velazquez H, Li Y, Wu Y, Desir GV: Catecholamines regulate the activity, secretion, and synthesis of renalase. Circulation 2008;117:1277-1282.

17 Desir GV, Tang L, Wang P, Li G, Sampaio-Maia B, Quelhas-Santos J, Pestana M, Velazquez H: Renalase lowers ambulatory blood pressure by metabolizing circulating adrenaline. J Am Heart Assoc 2012;1:e002634.

18 Beaupre BA, Hoag MR, Moran GR: Renalase does not catalyze the oxidation of catecholamines. Arch Biochem Biophys 2015;579:62-66.

19 Beaupre BA, Hoag MR, Roman J, Försterling FH, Moran GR: A metabolic function for human renalase: Oxidation of isomeric forms of $\beta$-NAD(P)H that are inhibitory to primary metabolism. Biochemistry 2015;57:795-806.

20 Han P, Sun H, Xu Y, Zeng Y, Yi W, Wu J, Shao M, Li S, Yi T: Lisinopril protects against the adriamycin nephropathy and reverses therenalase reduction: potential role of renalase in adriamycin nephropathy. Kidney Blood Press Res 2013;37:295-304.

21 Desir GV, Peixoto AJ: Renalase in hypertension and kidney disease. Nephrol Dial Transplant 2014;29:2228.

22 Wang F, Cai H, Zhao Q, Xing T, Li J, Wang N: Epinephrine evokes renalase secretion via $\alpha$-adrenoceptor/NFKB pathways in renal proximal tubular epithelial cells. Kidney Blood Press Res 2014;39:252-259.

23 Malyszko J, Zbroch E, Malyszko JS, Koc-Zorawska E, Mysliwiec M: Renalase, a novel regulator of blood pressure, is predicted by kidney function in renal transplant recipients. Transplant Proceed 2011;43:30043007.

24 Koc-Zorawska E, Malyszko J, Malyszko JS, Mysliwiec M: VAP-1, a novel molecule linked to endothelial damage and kidney function inkidney allograft recipients. Kidney Blood Press Res 2012;36:242-247.

25 Zbroch E, Malyszko J, Malyszko JS, Koc-Zorawska E, Mysliwiec M: Renalase, a novel enzyme involved in blood pressure regulation, is related to kidney function but not to blood pressure in hemodialysis patients. Kidney Blood Press Res 2012;35:395-399.

26 Wang F, Li J, Xing T, Xie Y, Wang N: Serum renalase is related to catecholamine levels and renal function. Clin Exp Nephrol 2014;19:92-98. 


\section{Kidney \\ Blood Pressure Research}

27 Wang Y, Xie BQ, Gao WH, Yan DY, Zheng WL, Lv YB, Cao YM, Hu JW, Yuan ZY, Mu JJ: Effects of reninangiotensin system inhibitors on renal expression of renalase in Sprague-Dawley rats fed with high salt diet. Kidney Blood Press Res 2015;40:605-613.

28 Li X, Xie Z, Lin M, Huang R, Liang Z, Huang W, Jiang W: Renalase protects the cardiomyocytes of SpragueDawley rats against ischemia and reperfusion injury by reducing myocardial cell necrosis and apoptosis. Kidney Blood Press Res 2015;40:215-222.

29 Wang F, Xing T, Li J, Bai M, Hu R, Zhao Z, Tian S, Zhang Z, Wang N: Renalase's expression and distribution in renal tissue and cells. PLoS ONE 2012;7:e46442.

30 Laemmli UK: Cleavage of structural proteins during the assembly of the head of bacteriophage T4. Nature 1970;227:680-685.

31 Gallagher S, Winston SE, Fuller SA, Hurrell JG: Immunoblotting and Immunodetection. Cur Protoc Cell Biol 2011, Doi 10.1002/0471143030.cb0602s52.

32 Fedchenko VI, Buneeva OA, Kopylov AT, Kaloshin AA, Axenova LN, Zgoda VG, Medvedev AE: Mass spectrometry detection of monomeric renalase in human urine. Biomed Khim 2012;58:599-607.

33 Giglione C, Boularot T, Meinnel T: Protein N-terminal methionine excision. Cell Mol Life Sci 2004;61:14551474 .

34 Durocher Y, Peret S, Camen A: High-level and high-throughput recombinant protein production by transient transfection of suspension-growing human 293-EBNA1 cells. Nucl Acids Res 2002;30:e9.

35 Wang L, Velazquez H, Moeckel G, Chang J, Ham A, Lee HT, Safirstein R, Desir GV: Renalase prevents AKI independent of amine oxidase activity. J Am Soc Nephrol 2014;25:1226-1235.

36 Wang L, Velazquez H, Chang J, Safirstein R, Desir GV: Identification of a receptor for extracellular renalase. PLoS One 2015;10:e0122932.

37 Guo X, Wang L, Velazquez H, Safirstein R, Desir GV: Renalase: its role as a cytokine, and an update on its association with type 1 diabetes and ischemic stroke. Curr Opin Nephrol Hypertens 2014;23:513-518.

38 Tojo A, Onozato ML, Kobayashi N, Goto A, Matsuoka H, Fujita T: Antioxidative effect of p38 mitogenactivated protein kinase inhibitor in the kidney of hypertensive rat. J Hypertens 2005;23:165-174. 